\title{
Energy Efficiency of Radiant Heating Systems Based on Water-Based Radiant Profiles
}

\author{
Mikhail Bodrov $^{1, *}$, Aleksandr Smykov ${ }^{1}$, Maksim Morozov $^{1}$, Anatoly Shapoval ${ }^{2}$, Victor Mironov $^{2}$ \\ ${ }^{1}$ Nizhny Novgorod State University of Architecture and Civil Engineering, 65, Ilyinskaya st., 603950 Nizhny Novgorod, Russian \\ Federation \\ ${ }^{2}$ IUT, Industrial University of Tyumen, 38, Volodarskogo st., 625000 Tyumen, Russian Federation
}

Received April 20, 2021; Revised June 2, 2021; Accepted July 19, 2021

\section{Cite This Paper in the following Citation Styles}

(a): [1] Mikhail Bodrov, Aleksandr Smykov, Maksim Morozov, Anatoly Shapoval, Victor Mironov, "Energy Efficiency of Radiant Heating Systems Based on Water-Based Radiant Profiles" Civil Engineering and Architecture, Vol. 9, No. 5, pp. 1546 - 1557, 2021. DOI: 10.13189/cea.2021.090525.

(b): Mikhail Bodrov, Aleksandr Smykov, Maksim Morozov, Anatoly Shapoval, Victor Mironov (2021). Energy Efficiency of Radiant Heating Systems Based on Water-Based Radiant Profiles. Civil Engineering and Architecture, 9(5), 1546 - 1557. DOI: 10.13189/cea.2021.090525.

Copyright $\mathrm{C} 2021$ by authors, all rights reserved. Authors agree that this article remains permanently open access under the terms of the Creative Commons Attribution License 4.0 International License

\begin{abstract}
It is repeatedly proved that the application of the radiant heating system is cost-effective. The most energy-efficient solution is the use of gas infrared emitters. In this case, there is no intermediate heating medium, and the heat of combustion of the gas enters the premises. However, this solution has a number of restrictions on the availability of natural gas, comfort, and fire hazard. Also, a highly efficient solution is the use of water infrared emitters, which can be radiant panels or radiant profiles that use an intermediate heating medium but do not have many of the limitations inherent in gas systems. A common problem for all types of radiant heating is the lack of a scientifically grounded and generally accepted engineering methodology for its design. Most of the regulatory documents simply do not take into account the peculiarities of the operation of radiant heating systems and, thus, do not allow a number of its advantages to be realized. This research was carried out based on NNGASU Radiant Heating Laboratory, unique in Russia, and is devoted to the peculiarities of the formation of the temperature regime in the premises heated by water infrared emitters, as well as the thermal regime of external enclosing structures in these premises.
\end{abstract}

Keywords Thermal Physics, Radiant Heating, Water Heating, Infrared Radiation, Emitter, Energy Efficiency

\section{Introduction}

Due to the constantly increasing energy prices and the growing technological requirement for energy is, the problem of energy conservation is one of the most acute in the construction industry, not only in Russia, but throughout the world [1]. A large quantity of energy resources is spent on heating large-volume industrial premises. The use of infrared heating systems is one of the most promising ways to increase the energy efficiency of such premises [2]. It deserves special attention [3], because in comparison with convective heating systems, it requires less heat consumption without reducing the level of thermal comfort.

The fundamental difference between heating systems based on infrared emitters is that heat is supplied to the working area by a directed flow of thermal radiation [4]. At the same time, the air is transparent to electromagnetic radiation in the infrared spectrum, only scattering it, and the energy from the infrared emitters accumulates on the near-surface layers of the irradiated surfaces, and then forms convective flows that heat the air of the working area. These features indicate a fundamental difference from convective heating systems and lead to an increase in energy efficiency [5].

There are various infrared heating devices on the market, classified by the temperature of the emitter surface. So, distinguish: 
- $\quad \operatorname{light}\left(\tau=400-1200^{\circ} \mathrm{C}\right)$;

- $\operatorname{dark}\left(\tau=200-400^{\circ} \mathrm{C}\right)$;

- low temperature $\left(\tau=30-200^{\circ} \mathrm{C}\right)$.

The most energy-efficient type of infrared heating is heating based on gas infrared emitters of the «light» and «dark» type [6]. In such systems, there is no intermediate heating medium (water, steam), so heat energy enters the room directly from the combustion of the primary energy carrier - natural gas. But the use of such systems is associated with some difficulties, for example, the use of any types of gas infrared emitters in rooms with increased fire safety requirements is prohibited [7]. In addition, the use of «light» gas infrared emitters is associated with the emission of exhaust gases directly into the volume of the serviced room, which leads to an increase in the cost of the forced ventilation system in premises. Also, gas connection in many regions is difficult and may be financially unjustified.

The most effective type of radiant heating, the use of which is not limited, are radiant heating systems based on water-based infrared emitters [8]. Heating devices in these systems are radiant panels (Figure 1a) or radiant profiles (Figure 1b), and the heating medium is hot water with a temperature of $40^{\circ} \mathrm{C}$ to $150{ }^{\circ} \mathrm{C}$. Thermal energy is transferred from the heating medium to the heating device, and it, in turn, emits electromagnetic waves in the infrared range, thereby providing heating of the serviced premises.

The main disadvantages of radiant panels, in comparison with radiant profiles are:

- a larger number of structural elements;

- more complex hydraulic mode;

- high construction weight;

- less reliability due to the complexity of the design;

- lower specific heat transfer.

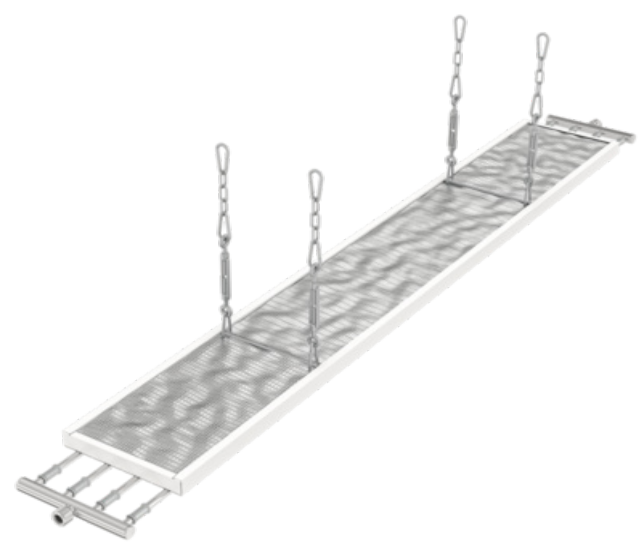

a
- At the same time, the use of heating systems based on water-based radiant profiles has a number of advantages:

- low thermal inertia, which ensures a short turn-on time;

- simple and effective hydraulic regulation, due to a smaller amount of heating medium;

- ease of installation and maintenance, due to a multiple reduction in the length of transit pipelines;

- saving space;

- long service life.

Radiant profiles are becoming more and more widespread in the market of heating devices in Europe and the world; but in Russia, due to the above disadvantages, they have not yet received proper distribution. The lack of a proven and scientifically-based methodology for designing heating systems based on radiant profiles is one of the reasons for the low distribution of systems of this type.

A number of works carried out in Russia have already proved that the use of heating systems based on water-based infrared emitters is effective and economically justified in large-volume premises, such as: industrial premises; showrooms; buildings of transport infrastructure; sports complexes, etc. [2, 6, 8]. As a result, Nizhny Novgorod State University of Architecture and Civil Engineering and Flaig + Hommel Russia LLC created the educational and research center «Heating Systems Using Low-Temperature Infrared Emitters» to conduct a complex of studies of a model of a radiant heating system based on radiant profiles with water as heating medium, and introduce them to the Russian market. The Center is based on the Radiant Heating Laboratory (Figure 2), equipped with the necessary instrumentation base.

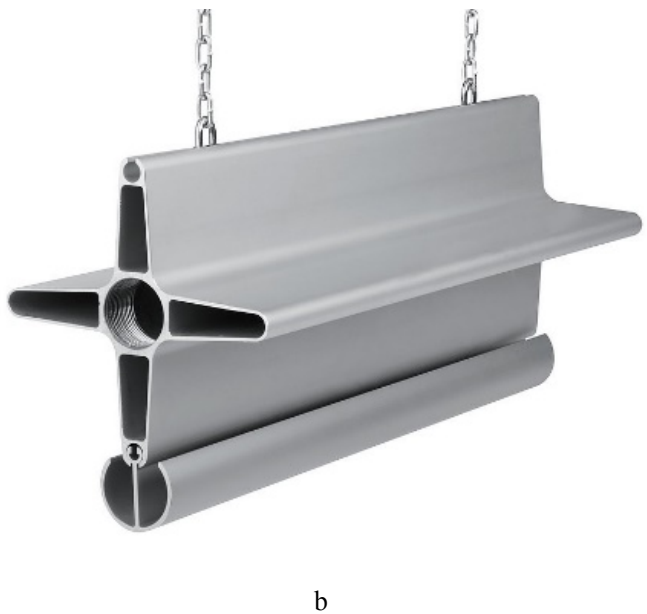

Figure 1. Infrared heating devices: $a$ - water-based radiant panel; $b$ - water-based radiant profile 

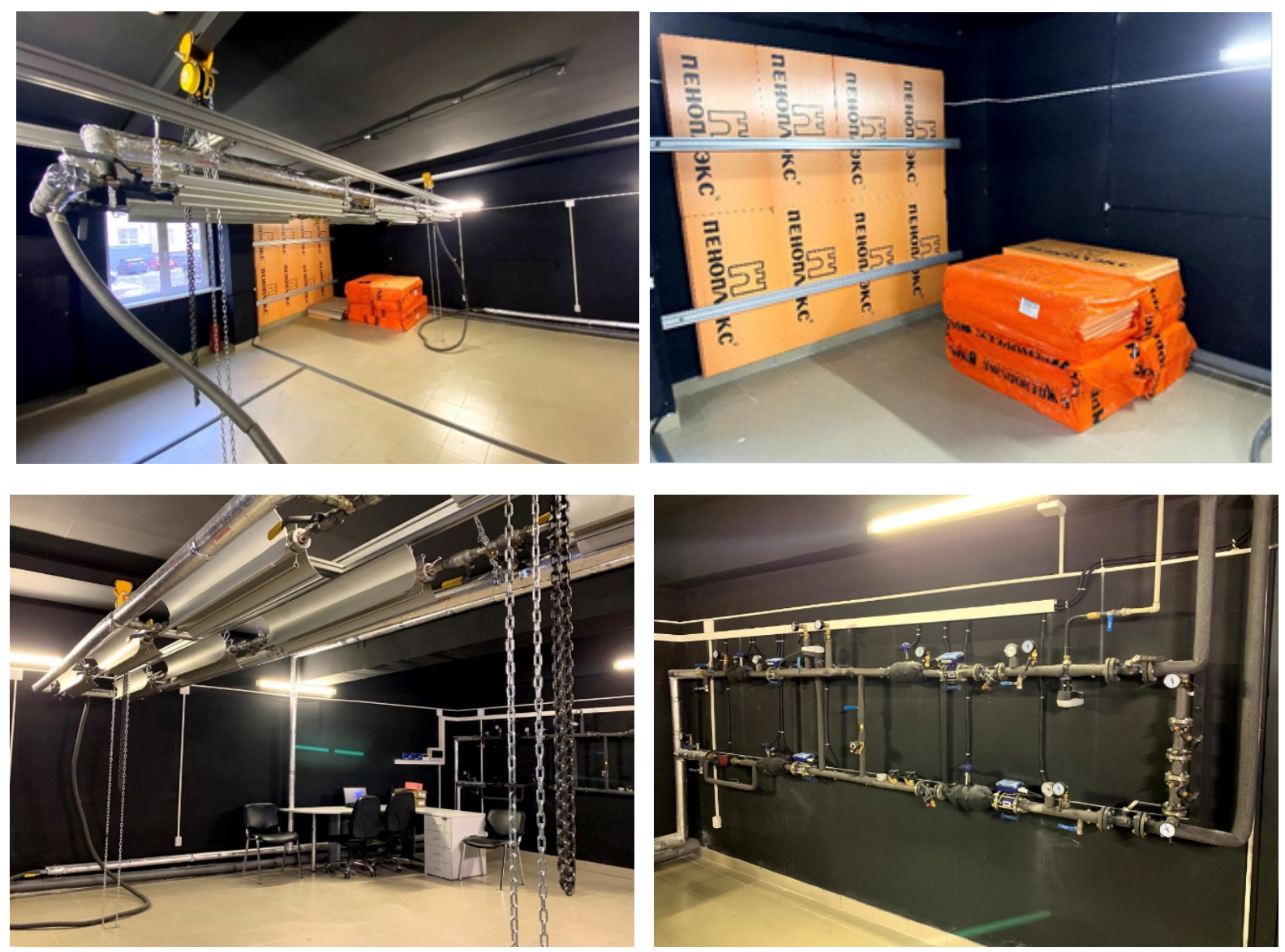

Figure 2. General view of the Radiant Heating Laboratory

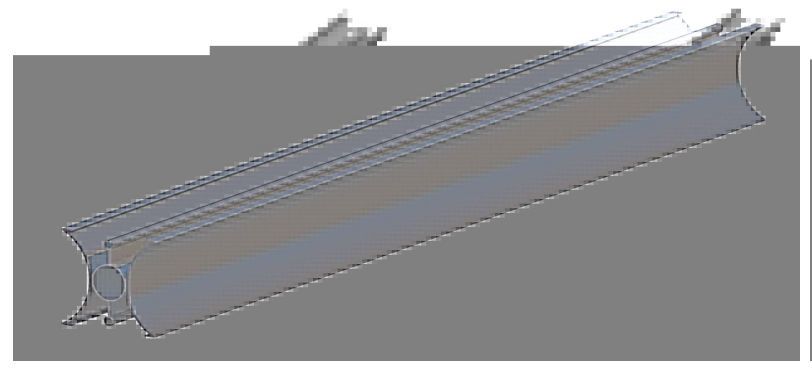

a

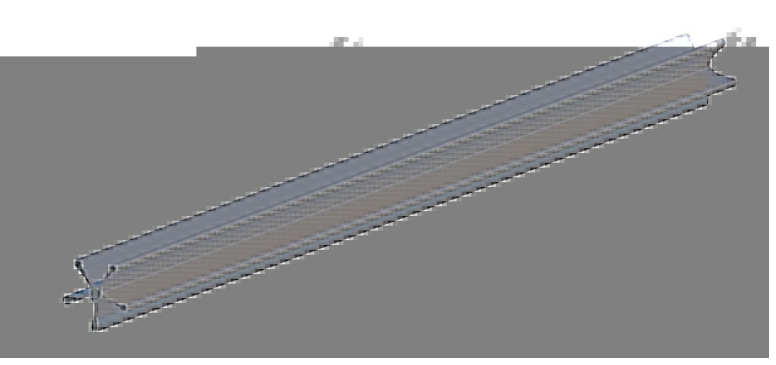

b

Figure 3. Radiant profiles: $\mathrm{a}$ - the Helios 750 brand; $\mathrm{b}$ - the Flower 125 brand

To create a complete picture of the operation of a heating system based on water-based radiant profiles, the following experimental studies are required:

- determination of the specific heat transfer of the radiant profile;

- research of the thermal regime of the heated room;
- research of the thermal and temperature conditions of the enclosing structures of the serviced premises.

The object of research was the radiant profiles of the Helios 750 brand (developed in Germany) and the Flower 125 brand (developed in Russia ). The models differ in size and shape (Table 1). Both models are manufactured at the Flaig + Hommel Russia LLC factory (Figure 3). 
Table 1. Characteristics of emitters - objects of research

\begin{tabular}{|c|c|c|c|}
\hline \multirow{2}{*}{ Characteristics } & \multirow{2}{*}{$\begin{array}{c}\text { Units of } \\
\text { measurement }\end{array}$} & \multicolumn{2}{|c|}{ Brand of the emitter } \\
\hline & & Helios 750 & Flower 125 \\
\hline Profile & - & & \\
\hline Material & - & AlMgSi0,5 & $\mathrm{AlMgSi} 0,5$ \\
\hline Sizes & $\mathrm{mm}$ & $170 \times 170$ & $125 \times 125$ \\
\hline Specific area & $\mathrm{m}^{2} / \mathrm{m}$ & 1,3 & 0,603 \\
\hline $\begin{array}{l}\text { Specific } \\
\text { capacity }\end{array}$ & $1 / \mathrm{m}$ & 2,6 & 0,28 \\
\hline $\begin{array}{l}\text { Specific gravity } \\
\text { of the profile }\end{array}$ & $\mathrm{kg} / \mathrm{m}$ & 7,1 & 3,6 \\
\hline $\begin{array}{c}\text { Specific gravity } \\
\text { of the profile } \\
\text { with water }\end{array}$ & $\mathrm{kg} / \mathrm{m}$ & 9,2 & 3,98 \\
\hline Connection & in & 2 & $1 / 2$ \\
\hline $\begin{array}{c}\text { Maximum } \\
\text { operating } \\
\text { pressure } \\
\end{array}$ & bar & 10 & 10 \\
\hline $\begin{array}{c}\text { Maximum } \\
\text { operating } \\
\text { temperature of } \\
\text { the heating } \\
\text { medium } \\
\end{array}$ & ${ }^{\circ} \mathrm{C}$ & 150 & 150 \\
\hline
\end{tabular}

\section{Materials and Methods}

Characteristics of the investigated emitter of the Helios 750 brand are as follows: width $-170 \mathrm{~mm}$; height -170 $\mathrm{mm}$; length - $1000 \mathrm{~mm}$; profile material - anodized aluminum alloy (AlMgSi0,5); maximum operating pressure - 10 bar; the maximum temperature of the supplied heating medium is limited only by the characteristics of the heat source because the alloy is not subject to corrosion and high-temperature electron emission.
Characteristics of the investigated emitter of the Flower 125 brand are as follows: width $-125 \mathrm{~mm}$; height -125 $\mathrm{mm}$; length - $1000 \mathrm{~mm}$; profile material - anodized aluminum alloy (AlMgSi0,5); maximum operating pressure - 10 bar; the maximum temperature of the supplied heating medium is limited only by the characteristics of the heat source because the alloy is not subject to corrosion and high-temperature electron emission.

These samples have different standard sizes and allow to simulate a fragment of a radiant water heating system based on water infrared emitters, apply test methods known in this field, and obtain experimental data that are scalable for the creation and improvement of methods for designing radiant heating systems.

\subsection{Research of the Specific Heat Transfer of Emitters}

The purpose of the research is to determine the specific heat transfer of $1 \mathrm{~m}$ of the emitter $q_{\mathrm{rad}}$ and compare this characteristic with other brands of water infrared emitters. The measurements were made using an electromagnetic flow meter-counter of the (ERSV-570F) brand and a heat quantity calculator (TRSV-026M), manufactured by «Vzlet», Ltd., the test setup diagram is shown in Figure 4. Measured values: $T_{1}$ - temperature of the heating medium in the supply pipeline of the test setup, ${ }^{\circ} \mathrm{C} ; T_{2}-$ the temperature of the heating medium in the return pipeline of the test setup, ${ }^{\circ} \mathrm{C} ; G_{1}-$ the mass flow rate of the heating medium in the supply pipeline of the test setup, $\mathrm{kg} / \mathrm{h} ; G_{2}$ - the mass flow rate of the heating medium in the return pipeline of the test setup, $\mathrm{kg} / \mathrm{h} ; N-$ the number of worked emitters, pcs; $Q_{\mathrm{tr}}-$ transit heat losses, W, measured experimentally.

The equation for the specific heat transfer of $1 \mathrm{~m}$ of the emitter for our test setup:

$$
q_{\mathrm{rad}}=\left(\frac{G_{1} \cdot \mathrm{C}_{\mathrm{T}_{1}} \cdot T_{1}}{3,6}-\frac{G_{2} \cdot \mathrm{C}_{2} \cdot T_{2}}{3,6}-Q_{\mathrm{tr}}\right) / N,
$$

where $\mathrm{c}_{\mathrm{T}_{1}}$ and $\mathrm{c}_{\mathrm{T}_{2}}$ are the heat capacity of water in the supply and return pipelines, respectively, $\mathrm{kJ} / \mathrm{kg}^{\circ} \mathrm{C}$. 

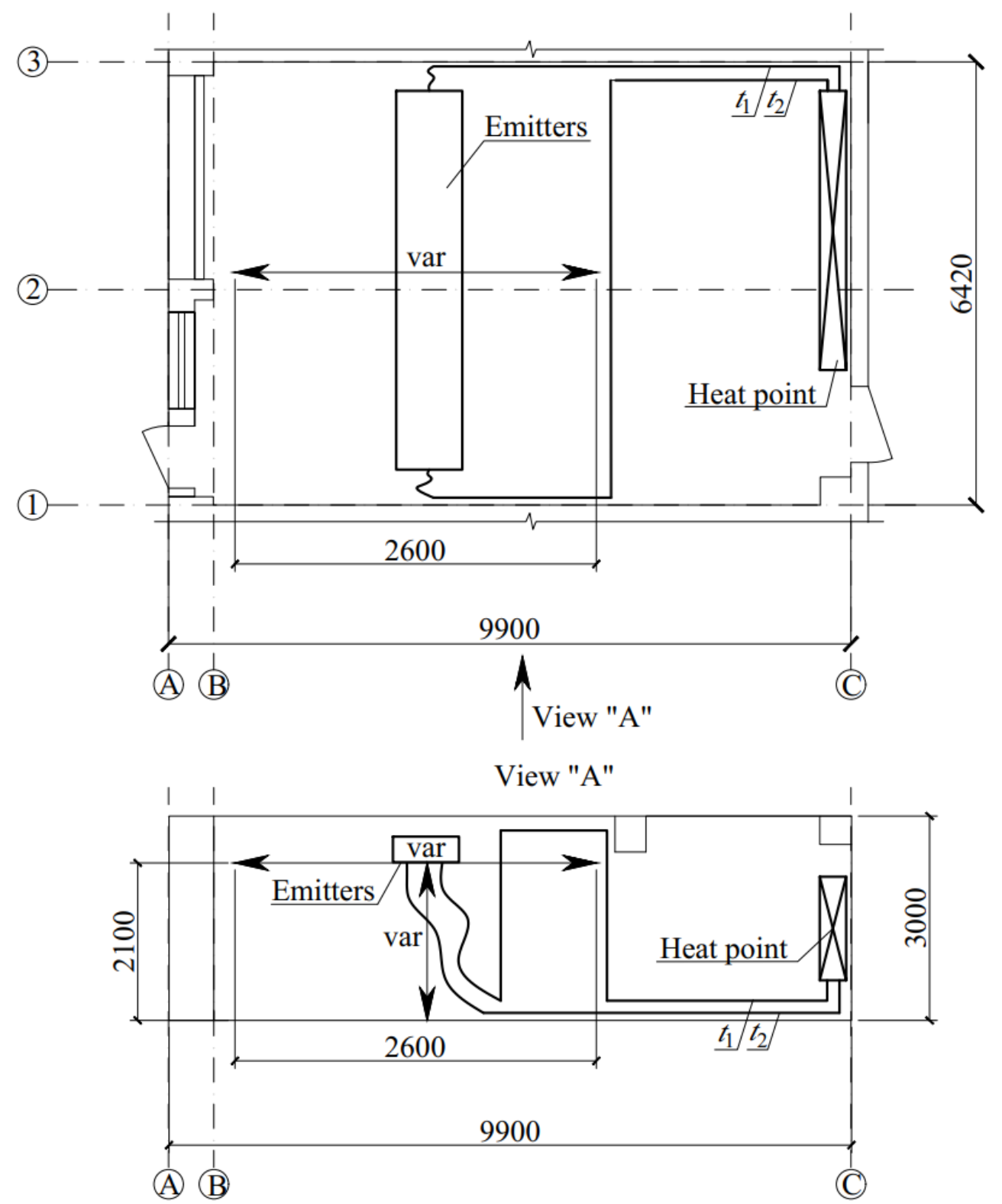

Figure 4. Scheme of the test setup for the research of heat transfer of emitters (layout and view «A») 


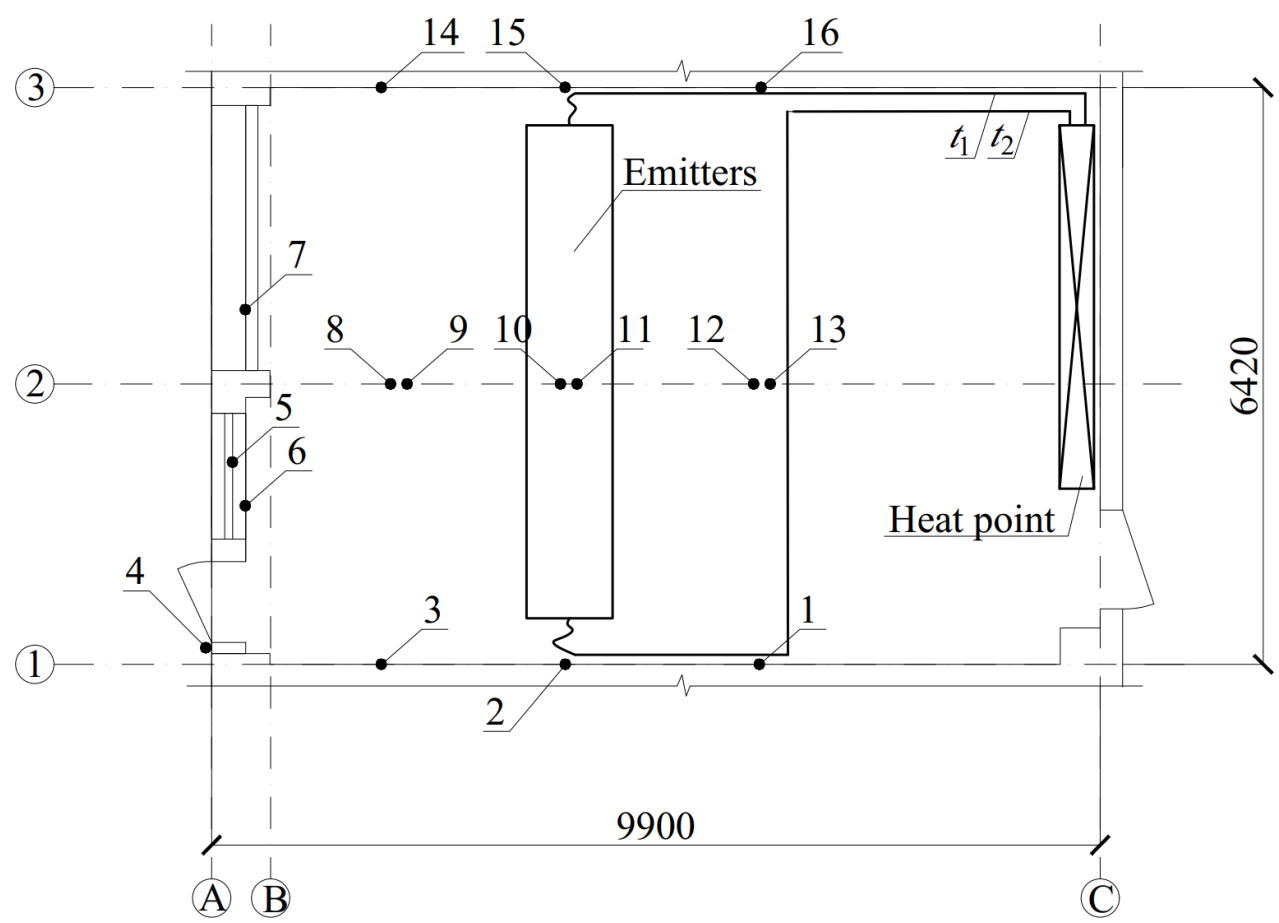

Figure 5. Layout of temperature sensors in the laboratory: 1 - on the wall, 2 - on the wall, 3 - on the wall, 4 - on the street, 5 - on the window, 6 under the window on the wall, 7 - on the wall (under the insulation), 8 - on the floor, 9 - on the ceiling, 10 - on the floor, 11 - on the ceiling, 12 - on the floor, 13 - on the ceiling, 14 - on the wall, 15 - on the wall, 16 - on the wall

\subsection{Research of the Room Temperature Regime}

The purpose of the research is to determine the differences in the formation of the temperature regime in a room with radiant heating and convective heating. The object of research of the temperature regime was the premise of the Radiant Heating Laboratory of NNGASU. In the premise with a height of $3.0 \mathrm{~m}$, in addition to a setup with infrared emitters and two radiators, there are 16 sensors (TS-1388/12) connected to a multichannel thermometer (TM 5104D/V/t1050/GP), manufactured by «Elemer» Ltd. The layout of the sensors in the laboratory is shown in Figure 5.

The experiments were carried out in two stages: at the $1^{\text {st }}$ stage, a suspended setup with 6 water infrared emitters Flower 125, $1 \mathrm{~m}$ each, was used to heat the premises; at the $2^{\text {nd }}$ stage, the room was heated by two bimetallic radiators (Calidor 500 brand), 12 sections each.

\subsection{Research of the Thermal Regime of External Enclosing Structures}

The purpose of the research is to study the effect of radiant heating on the heat-shielding characteristics of external enclosing structures. The object of research on the thermal regime was the vertical external enclosing structure - the wall of the Radiant Heating Laboratory of NNGASU. This wall is also part of a laboratory setup and is equipped with a system that allows to vary the thickness of the insulation. At the time of the experiment, insulation of the «Penoplex Osnova» brand was installed with a thermal conductivity coefficient $\lambda=0.032 \mathrm{~W} /\left(\mathrm{m} \cdot{ }^{\circ} \mathrm{C}\right)$ and a thickness of $\delta=0.05 \mathrm{~m}$. The measuring equipment used was a device for measuring heat flow («Teplograph» brand), which includes a module- 02 , sensors connected to this module also allow to measure the temperature of surfaces and the environment. Measurements were carried out in accordance with [9]. The scheme of the experiment is shown in Figure 6 and Figure 7. 


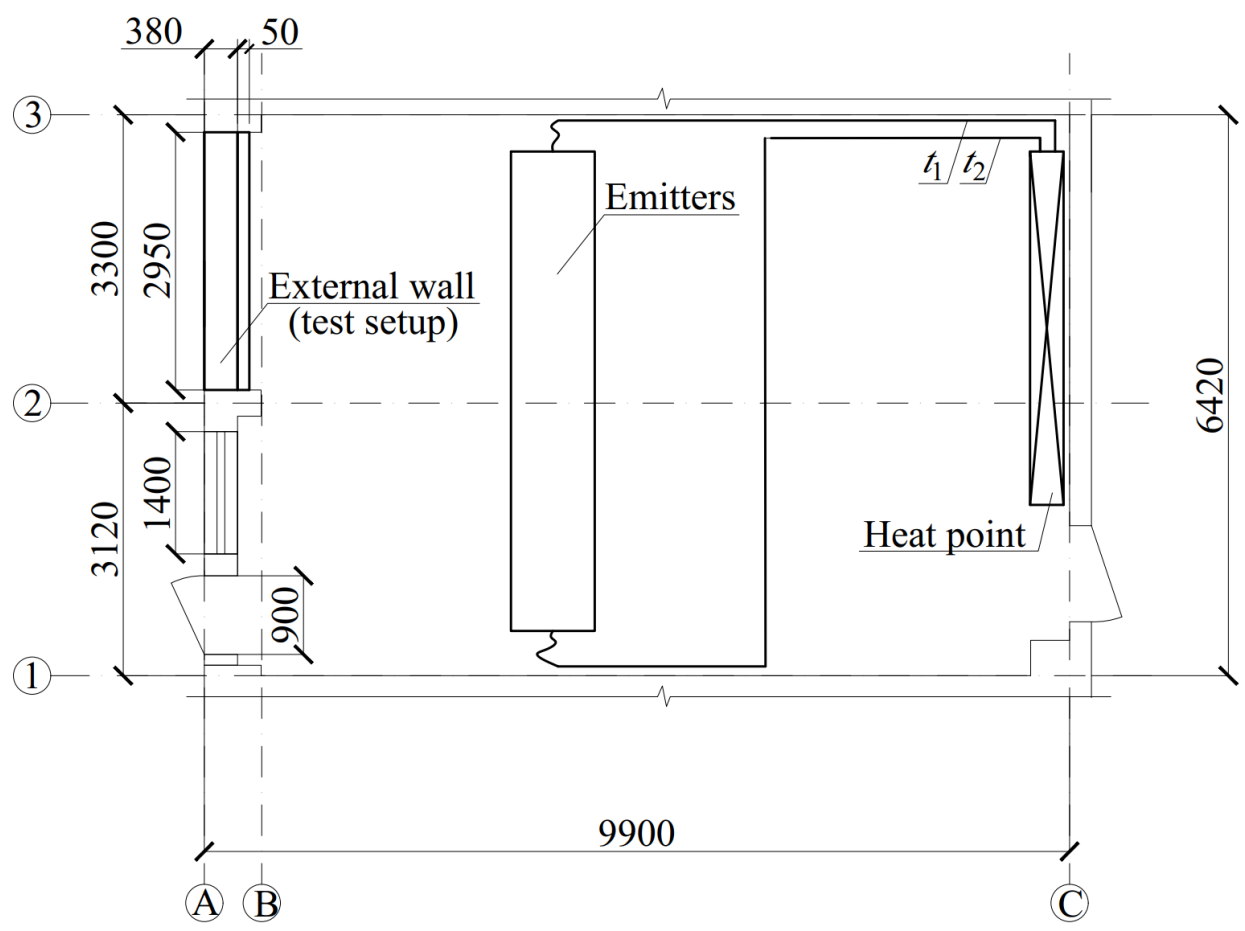

Figure 6. Plan of the Radiant Heating Laboratory of NNGASU

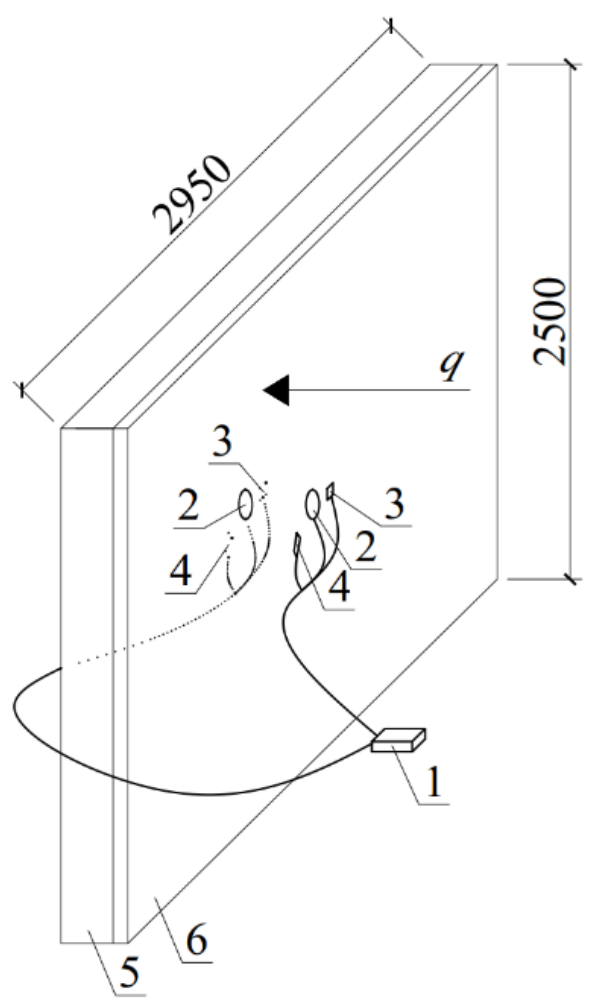

Figure 7. Test setup consisting of: 1 - device «Teplograph»; 2 - heat flow density sensors; 3 - surface temperature sensors; 4 - air temperature sensors; 5 - silicate brick wall; 6 - insulation «Penoplex Osnova» The experiments were carried out in two stages: at the $1^{\text {st }}$ stage, a suspended setup with 6 water infrared emitters Flower 125, 1 m each, was used to heat the premises; at the $2^{\text {nd }}$ stage, the premise was heated by two bimetallic radiators (Calidor 500 brand), 12 sections each.

\section{Results and Discussion}

As a result of the planning of experimental studies, the minimum required number of experiments and the methodology for using the apparatus of mathematical statistics to formalize the results of the experiment are determined.

In scientific and technical research, the following method for determining the minimum number of measurements $n_{\text {meas }}$ is used and sufficient.

The average value $\bar{x}$ of the measured value $x$, the corrected variance $s^{2}$ and the mean square deviation $\sigma$ are calculated using the following formulas:

$$
\begin{gathered}
\overline{\mathrm{x}}=\frac{\sum_{\mathrm{i}=1}^{\mathrm{n}_{\text {meas }} \mathrm{x}_{\mathrm{i}}}}{\mathrm{n}_{\text {meas }}} ; \\
\mathrm{s}^{2}=\frac{1}{\mathrm{n}_{\text {meas }}-1} \sum_{\mathrm{i}=1}^{\mathrm{n}_{\text {meas }}}\left(\mathrm{x}_{\mathrm{i}}-\overline{\mathrm{x}}\right)^{2} ; \\
\sigma=\sqrt{\mathrm{s}^{2}} .
\end{gathered}
$$

The minimum number of measurements must satisfy the condition:

$$
n_{\text {meas }} \geq\left(\frac{t_{\text {dist } \sigma}}{\beta_{0}}\right)^{2},
$$

where $t_{\text {dist }}$ is the value distributed according to the student's law, determined according to the number of degrees of freedom $v=n_{\text {meas }}-1$ and the significance level $q=(1-\alpha) 100 \% ; \beta_{0}, \alpha-$ are the confidence interval and the confidence probability, respectively.

The distribution according to the student's law is valid for the value $x$ distributed normally, which requires an estimate of the normality of the distribution, and is carried 
out using dimensionless combinations of the central moments of the distribution $A$ and $E$ according to the formulas:

$$
\begin{aligned}
& A=\frac{1}{s^{3}\left(n_{\text {meas }}-1\right)} \sum_{i=1}^{n_{\text {meas }}}\left(x_{i}-\bar{x}\right)^{3} ; \\
& E=\frac{1}{s^{4}\left(n_{\text {meas }}-1\right)} \sum_{i=1}^{n_{\text {meas }}}\left(x_{i}-\bar{x}\right)^{4} .
\end{aligned}
$$

The central moments $A$ and $E$ for normally distributed quantities are equal to zero. If, according to the calculation results, $A$ and $E$ are not equal to zero, the eigenvalue variance $D$ of the measured values is estimated:

$$
\begin{gathered}
D(A)=\frac{6\left(n_{\text {meas }}-1\right)}{\left(n_{\text {meas }}+1\right)\left(n_{\text {meas }}+3\right)} ; \\
D(E)=\frac{24 n_{\text {meas }}\left(n_{\text {meas }}-2\right)\left(n_{\text {meas }}-3\right)}{\left(n_{\text {meas }}+1\right)^{2}\left(n_{\text {meas }}+3\right)\left(n_{\text {meas }}+5\right)} .
\end{gathered}
$$

The distribution of the measured values is considered normal if the following conditions are met:

$$
\begin{array}{r}
|A| \leq 3 \sqrt{D(A)} \\
|E| \leq 5 \sqrt{D(E)} .
\end{array}
$$

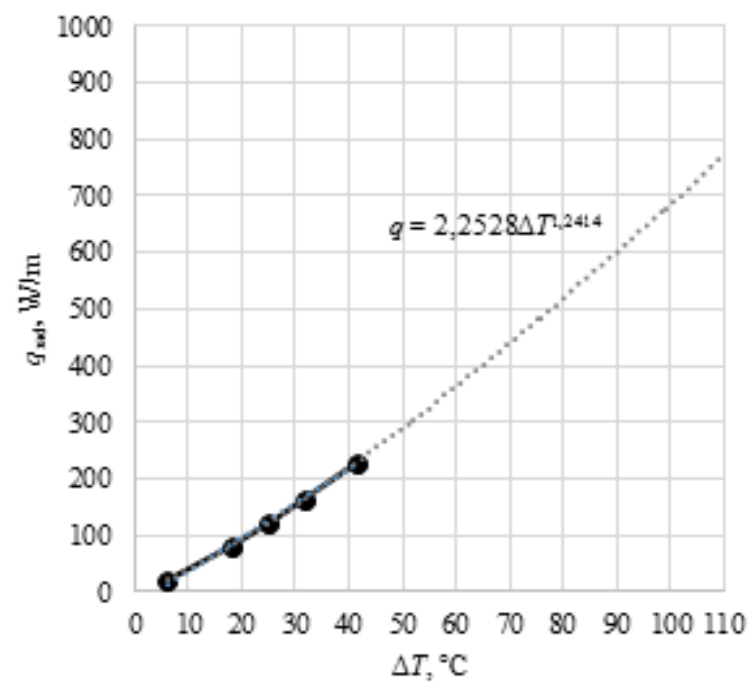

In the process of testing the models, we took the following number of identical measurements. The temperature of the heating medium $T_{1},{ }^{\circ} \mathrm{C}, T_{2},{ }^{\circ} \mathrm{C}$ was measured for three times; the flow rate of the heating medium $G_{1}, \mathrm{~kg} / \mathrm{h}, G_{2}, \mathrm{~kg} / \mathrm{h}$ was measured for three times; the total power of the system $Q_{\text {tot }}$, W was measured for three times; the density of the radiant heat flow $E_{\text {rad }}, \mathrm{W} / \mathrm{m}^{2}$ was measured for three times. Below are the results of experiments that have undergone mathematical processing.

\subsection{Research of the Specific Heat Transfer of Emitters}

The research conducted to determine the specific thermal power of $1 \mathrm{~m}$ of emitters were subjected to mathematical processing by two methods: mathematical modeling of the trend line in the MathCAD software package and the construction of a linear regression on a logarithmic scale. The results of the Helios 750 research before and after mathematical processing are shown in Figure 8 and Table 2.

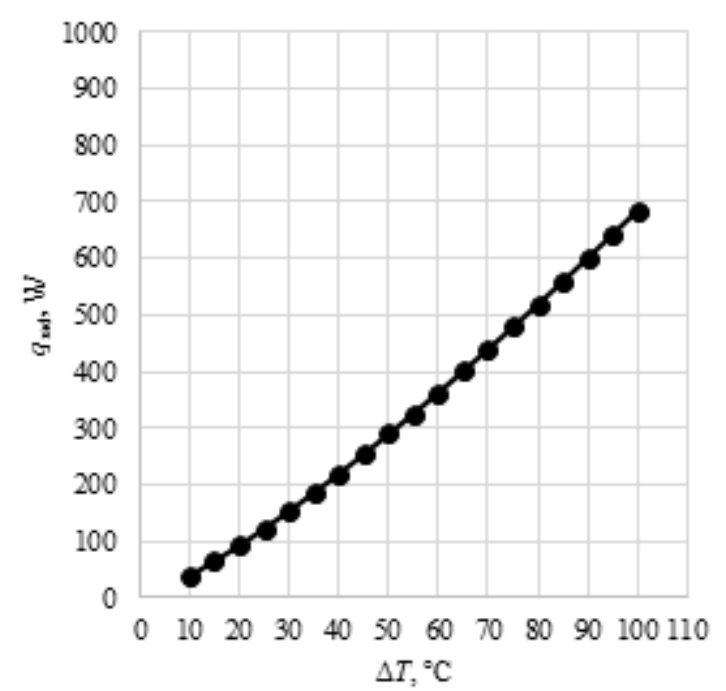

Figure 8. The Research results of the specific thermal power of the Helios 750 emitter: $a$ - after determining the error; $b$ - after mathematical processing

Table 2. The specific power of Helios 750 at fixed values $\Delta T$

\begin{tabular}{|c|c|c|c|c|c|c|c|c|c|c|c|c|c|c|c|c|c|c|c|}
\hline $\begin{array}{c}\Delta T, \\
{ }^{\circ} \mathrm{C}\end{array}$ & 10 & 15 & 20 & 25 & 30 & 35 & 40 & 45 & 50 & 55 & 60 & 65 & 70 & 75 & 80 & 85 & 90 & 95 & 100 \\
\hline $\begin{array}{c}q_{\text {rad }} \\
\mathrm{W} / \mathrm{m}\end{array}$ & 50,46 & 83,51 & 119,38 & 157,52 & 197,56 & 239,26 & 282,43 & 326,94 & 372,66 & 419,50 & 467,39 & 516,26 & 566,04 & 616,70 & 668,18 & 720,45 & 773,47 & 827,21 & 881,64 \\
\hline
\end{tabular}



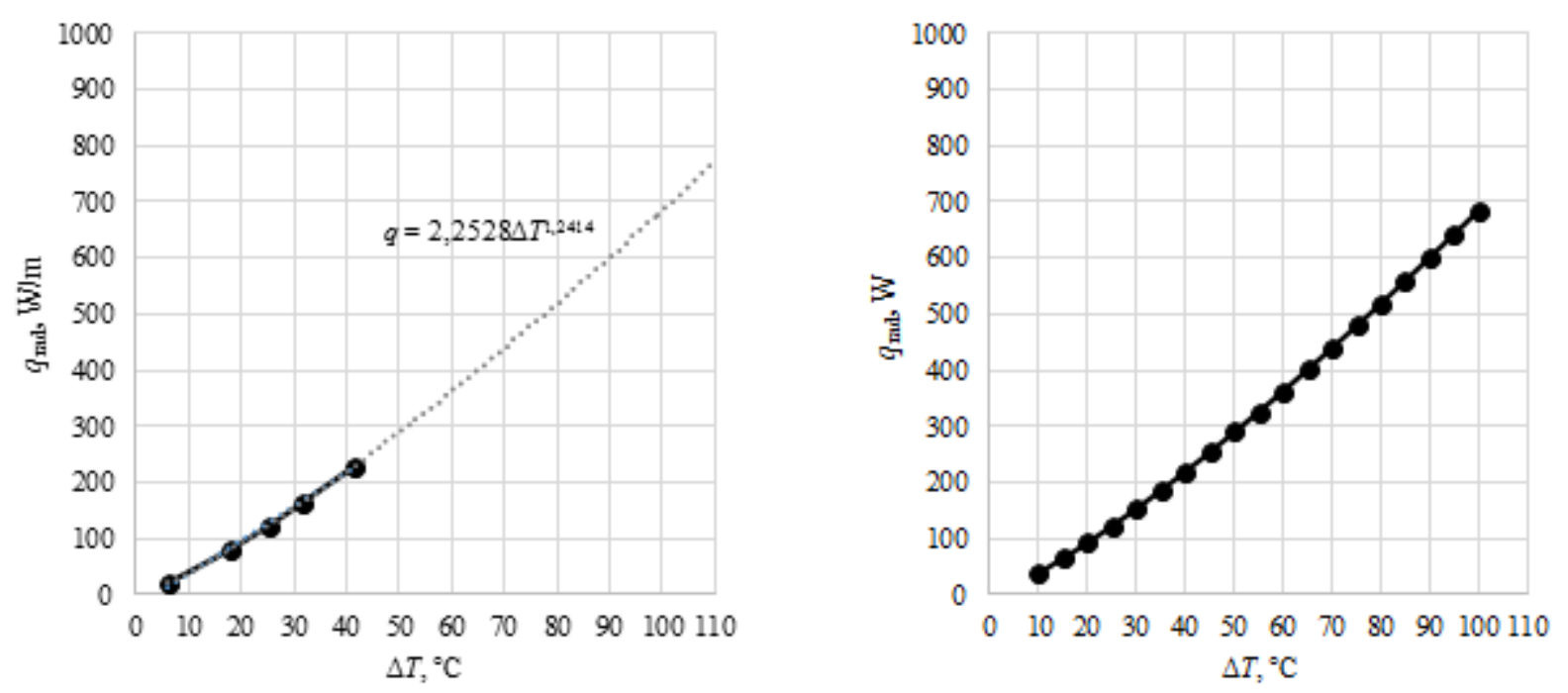

Figure 9. The Research results of the specific thermal power of the Flower 125 emitter: a - after determining the error; $b$ - after mathematical processing

Table 3. The specific power of Flower 125 at fixed values $\Delta T$

\begin{tabular}{|c|c|c|c|c|c|c|c|c|c|c|c|c|c|c|c|c|c|c|c|}
\hline $\begin{array}{c}\Delta T, \\
{ }^{\circ} \mathrm{C}\end{array}$ & 10 & 15 & 20 & 25 & 30 & 35 & 40 & 45 & 50 & 55 & 60 & 65 & 70 & 75 & 80 & 85 & 90 & 95 & 100 \\
\hline $\begin{array}{c}q_{\text {rad }} \\
\mathrm{W} / \mathrm{m}\end{array}$ & 39,28 & 64,98 & 92,87 & 122,51 & 153,63 & 186,03 & 219,57 & 254,15 & 289,66 & 326,04 & 363,24 & 401,19 & 439,85 & 479,18 & 519,15 & 559,73 & 600,89 & 642,61 & 684,86 \\
\hline
\end{tabular}

As a result of mathematical transformations, an equation was obtained for the specific power curve for the Helios 750:

$$
q_{\mathrm{rad}}^{H 750}=2,8881 \cdot \Delta T^{1,2423}
$$

The results of the Flower 125 research before and after mathematical processing are shown in Figure 9 and Table 3.

As a result of mathematical transformations, an equation was obtained for the specific power curve for the Flower 125:

$$
q_{\mathrm{rad}}^{F 125}=2,2528 \cdot \Delta T^{1,2414} .
$$

After analyzing the results obtained, we can conduct a comparative analysis of water infrared emitters on the market in Russia and the world (Table 4).
Table 4. Comparison of water-based infrared emitters of different brands

\begin{tabular}{|c|c|c|c|}
\hline $\begin{array}{c}\text { Brand } \\
\text { (production) }\end{array}$ & $\begin{array}{c}\text { Power of } 1 \mathrm{~m} \\
\text { of the device } \\
\text { at } \Delta T=55 \\
{ }^{\circ} \mathrm{C}, \mathrm{W}\end{array}$ & $\begin{array}{c}\text { The cost of } 1 \\
\text { m of the } \\
\text { device, USD }\end{array}$ & $\begin{array}{c}\text { Cost of 1 } \\
\text { W of } \\
\text { power, } \\
\text { USD }\end{array}$ \\
\hline $\begin{array}{c}\text { Helios 750 } \\
\text { (Russia) }\end{array}$ & $\mathbf{4 1 9 , 5 0}$ & $\mathbf{1 0 0}$ & $\mathbf{0 , 2 4}$ \\
\hline $\begin{array}{c}\text { Flower 125 } \\
\text { (Russia) }\end{array}$ & $\mathbf{3 2 6 , 0 4}$ & $\mathbf{6 5}$ & $\mathbf{0 , 2 0}$ \\
\hline $\begin{array}{c}\text { Teplopanel } \\
\text { TP-1 (Russia) }\end{array}$ & 248,00 & 80 & $\mathbf{0 , 3 3}$ \\
\hline $\begin{array}{c}\text { Zender ZBN } \\
\text { (Germany) }\end{array}$ & 264,00 & 150 & $\mathbf{0 , 5 7}$ \\
\hline
\end{tabular}



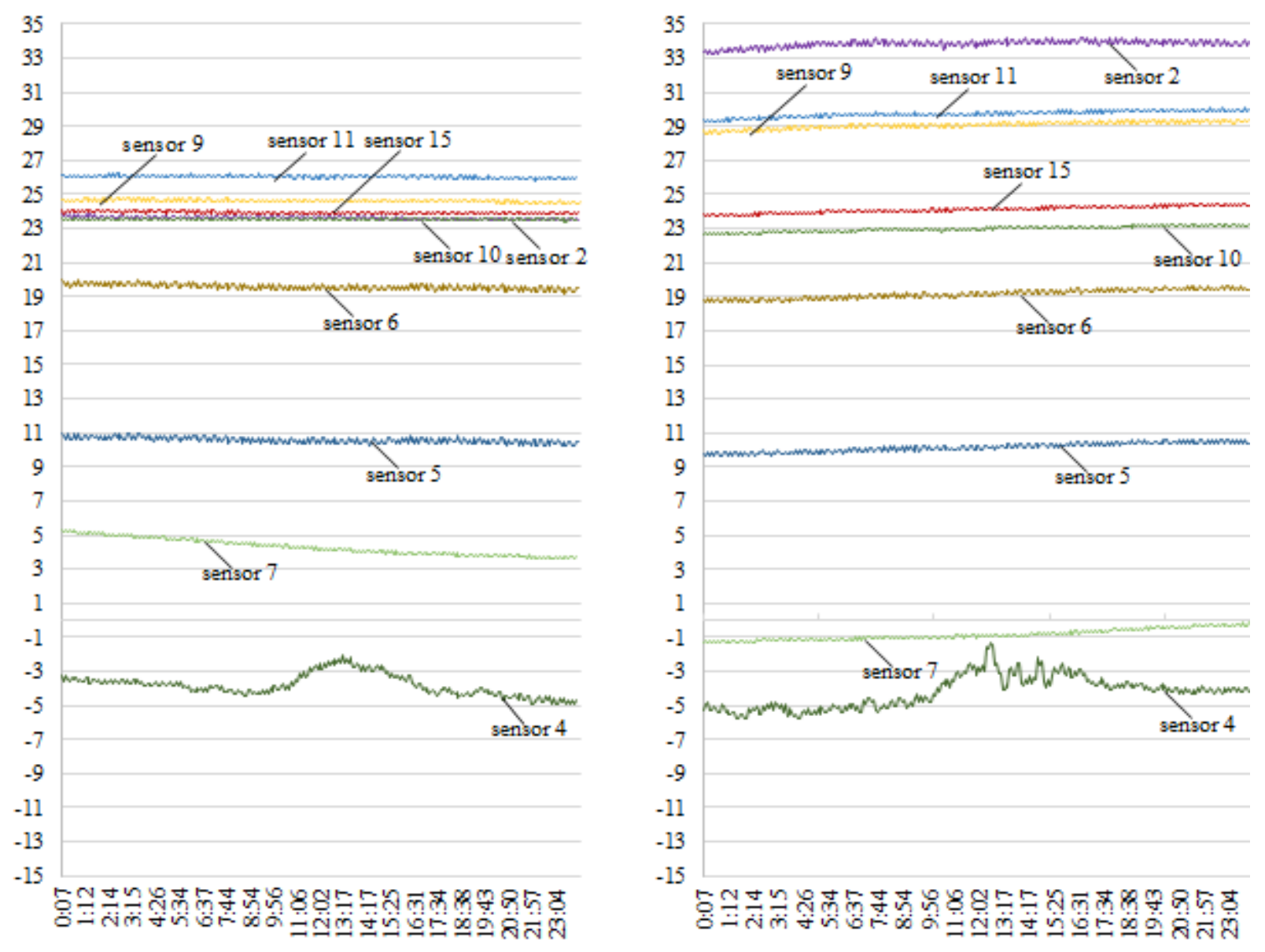

Figure 10. Indications of characteristic sensors in the study of the temperature regime of the room: $a-$ at the $1^{\text {st }}$ stage with radiant heating; $b-a t$ the $2^{\text {nd }}$ stage with convective heating

\subsection{Research of the Thermal Regime of External Enclosing Structures}

The result of the research of the temperature regime of the room under radiant heating and convective heating and the processing of the results obtained were as follows (Figure 10).

According to the results of the conducted analysis, the following conclusions can be drawn:

1. The indications of the sensors, located on the wall above the radiators during the $2^{\text {nd }}$ stage of the experiment, were significantly higher because they are located near the radiators.

2. The indications of the sensors, located on the wall free of heating devices, during the $1^{\text {st }}$ and $2^{\text {nd }}$ stages of the experiment differed slightly. As a result, we can talk about a similar temperature regime in the working area of the premises.

3. The indications of the sensors, located on the floor, in the case of using radiant heating are higher than in the case of using convective heating, which is attributed to the higher radiation density of the floor surface.

4. The indications of the sensors, which are located on external enclosing structures, are higher during radiant heating, due to the higher radiation density of the surface of the walls and window.

5. The indications of the sensors, located on the ceiling of the heated premises, in the case of using radiant heating are significantly lower than when using convective heating. A smaller temperature gradient may be noted when using radiant heating, even considering the fact that the sensors are additionally irradiated, and one of the sensors was located directly above the emitters.

\subsection{Research of the Thermal Regime of External Enclosing Structures}

During the experiments, two days were selected that were similar in climatic conditions. In addition, the temperatures of the supply of the heating medium were equalized, as well as the power of the radiant heating and convective heating systems. The research results are presented in Figure 11.

Based on the analysis of the graphs obtained, the following conclusions can be drawn:

1. As already mentioned in 3.2 - the lack of irradiation of the outer wall affected the indicators of the 
temperature sensors located on it, they significantly decreased.

2. The temperature head and, as a consequence, the heat flux during the $1^{\text {st }}$ stage of the experiment was higher than that in the $2^{\text {nd }}$ stage.

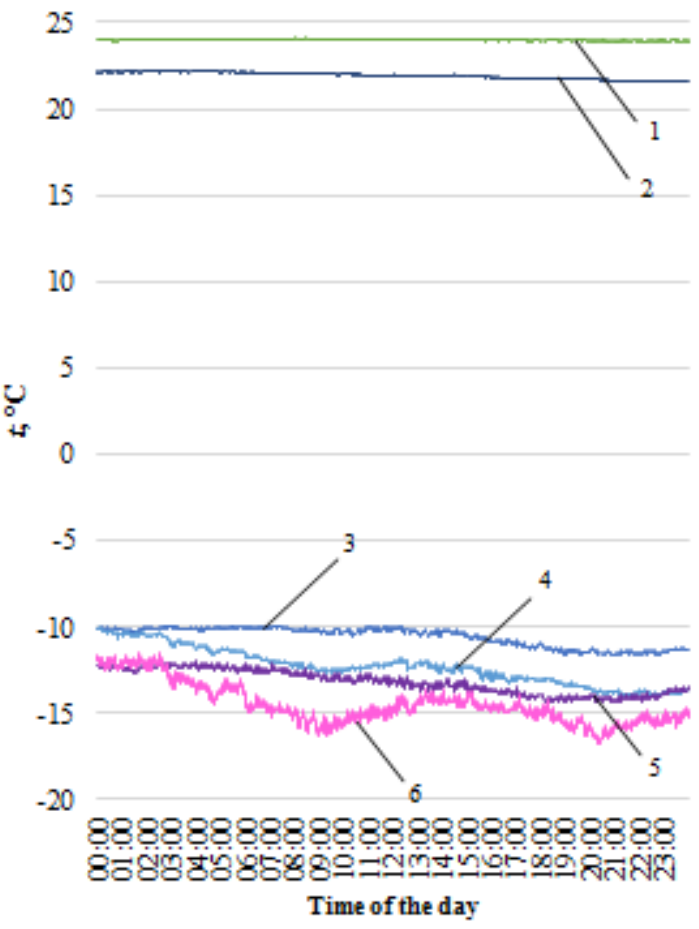

3. The temperature head between the temperature of the external surface and the temperature of the inner air during the $1^{\text {st }}$ stage of the experiment was higher than that in the $2^{\text {nd }}$ stage, which indicates a higher relative temperature of the external surface of the irradiated enclosure.

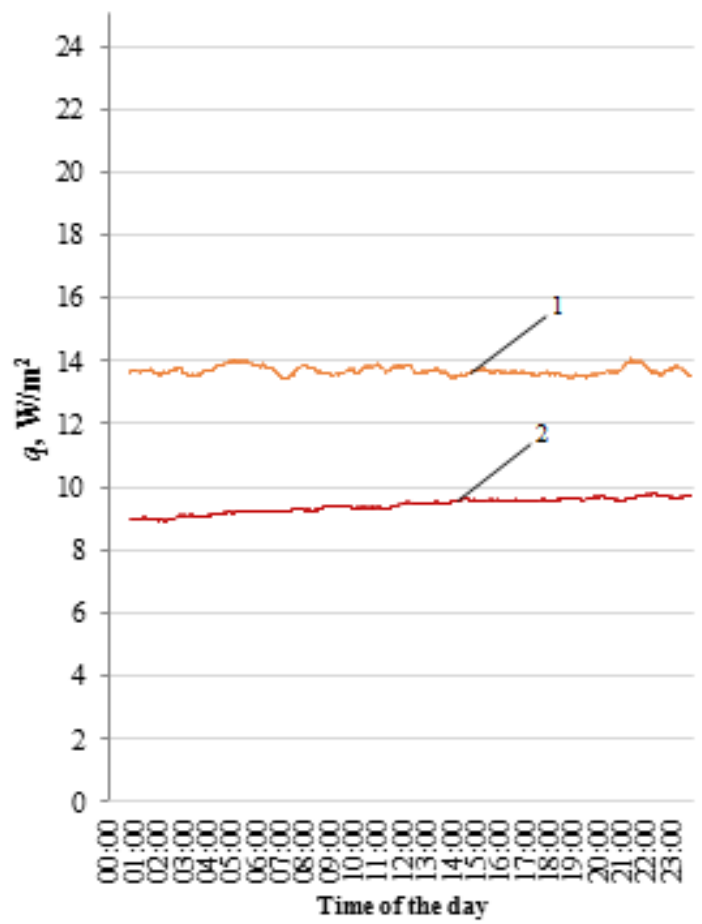

Figure 11. Sensor indications during the experiment. a - temperature sensor indications: 1 - temperature on the internal surface (the $1^{\text {st }}$ stage), 2 temperature on the internal surface (the $2^{\text {nd }}$ stage), 3 - temperature on the external surface (the $1^{\text {st }}$ stage), 4 -temperature on the external surface (the $2^{\text {nd }}$ stage), 5 - external air temperature (the $1^{\text {st }}$ stage), 6 - external air temperature (the $2^{\text {nd }}$ stage); $b$ - heat flow density sensor indications $\left(1-\right.$ at the $1^{\text {st }}$ stage with radiant heating; 2 - at the $2^{\text {nd }}$ stage with convective heating) 


\section{Conclusions}

1. Water infrared emitters of the Helios 750 and the Flower 125 brands produced in Russia have a specific power cost lower than that of competing water-based infrared panels.

2. The radiant heating system based on water-based infrared profiles allows reducing the air temperature gradient along the height in comparison with a convective heating system, not only in large-volume premises, such as: workshops, depots, gyms, but also in rooms with a low floor height. This feature allows you to reduce heat loss through the coating.

3. The system of water-based radiant heating, due to the high coefficient of radiant heat transfer, has a high density of infrared radiation, which, in turn, heats the surfaces of the external enclosures, that increases their temperature and helps protect the premises from condensation, but at the same time provokes large heat losses.

4. The temperature regime in the working area of the premise with the use of water radiant heating, in comparison with convective heating, remains unchanged ; but it is possible to reduce the internal temperature of the room, and that will not affect the thermal sensation of the person in it, allowing reducing transmission heat losses.

5. The high energy efficiency of the use of radiant heating systems based on water infrared emitters is achieved due to:

- a smaller temperature gradient along the height of the premise and the absence of a heat cushion, which reduces heat loss through the covering of the room;

- lowering the air temperature of the working area without reducing the level of comfort, due to a higher radiation temperature, which also reduces transmission heat losses;

- less thermal inertia, which allows to increase the standby time of the heating system and reduce the duration of the transient mode.

\section{Acknowledgements}

We thank Flaig + Hommel GmbH and Flaig + Hommel Russia LLC for the samples of Helios 750 and Flower 125 water infrared emitters provided for testing.

\section{REFERENCES}

[1] I. A. Bashmakov. Analysis of the main trends in the development of heat supply systems in Russia and abroad, News of heat supply, No. 2 (90), 2008.

[2] V. I. Bodrov, L. Yu. Mikhailova, A. A. Smykov. Temperature regime of external enclosures of premises with heating systems based on gas infrared emitters, Privolzhsky scientific journal, No. 2 (34), 58-64, 2015.

[3] V. I. Bodrov, V. F. Bodrova, A. A. Smykov. Research of the thermal regime of external enclosing structures in industrial premises with heating systems based on infrared emitters, Privolzhsky scientific journal, No. 2 (46), 23-36, 2018.

[4] V. I. Bodrov, M. V. Bodrov, A. A. Smykov. Research of radiant heating systems based on low-temperature infrared emitters, Privolzhsky scientific journal, No. 3 (51), 52-57, 2019.

[5] N. Fonseca. Experimental analysis and modeling of hydronic radiant ceiling panels using transient-state analysis, International Journal of Refrigeration, No. 4(34), 958-967, 2011. DOI: 10.1016/j.ijrefrig.2011.01.007.

[6] N. I. Kurilenko, G. Y. Mamontov, L. Y. Mikhaylova. Temperature patterns in the gas infrared radiator heating area, EPJ Web of Conferences. (82), 2015. DOI: 10.1051/epjconf/20158201006.

[7] G. V. Kuznetsov, N. I. Kurilenko, A. E. Nee. Mathematical modelling of conjugate heat transfer and fluid flow inside a domain with a radiant heating system, International Journal of Thermal Sciences. (131), 27-39, 2018. DOI: 10.1016/j.ijthermalsci.2018.05.010.

[8] M. V. Bodrov, V. Yu. Kuzin, M. S. Morozov, A. A. Smykov. Determination of the economic advantage of using radiant heating systems based on water infrared emitters, Theoretical foundations of heat and gas supply and ventilation. Collection of reports of the VIII All-Russian Scientific and Technical Conference dedicated to the centenary of the IISI-MGSU. Moscow, 14-19, 2020.

[9] Methodical recommendations for a comprehensive thermo-technical inspection of external enclosing structures using thermal imaging equipment. MDS 23-1.2007 / FSUE SRC "Construction", - Moscow: FSUE TsPP, 20, 2007. 